\title{
Agricultura Familiar, Extensão Rural e Soberania e Segurança Alimentar e Nutricional: delimitando categorias analíticas à luz da implementação do Programa de Aquisição de Alimentos no Brasil
}

Salgado, Rafael Junior dos Santos Figueiredo; Dias, Marcelo Miná; Souza, Washington José de Agricultura Familiar, Extensão Rural e Soberania e Segurança Alimentar e Nutricional: delimitando categorias analíticas à luz da implementação do Programa de Aquisição de Alimentos no Brasil Mundo Agrario, vol. 21, núm. 46, 2020

Universidad Nacional de La Plata, Argentina

Disponible en: http://www.redalyc.org/articulo.oa?id=84562590003

DOI: https://doi.org/10.24215/15155994e137

Esta obra está bajo una Licencia Creative Commons Atribución-NoComercial-Compartirlgual 4.0 Internacional. 


\title{
Agricultura Familiar, Extensão Rural e Soberania e Segurança Alimentar e Nutricional: delimitando categorias analíticas à luz da implementação do Programa de Aquisição de Alimentos no Brasil
}

\author{
Family Agriculture, Rural Extension and Sovereignty and Food and Nutrition Security: delimiting analytical \\ categories in light of the implementation of the Food Acquisition Program in Brazil
}

Rafael Junior dos Santos Figueiredo Salgado

Universidade Federal do Rio Grande do Norte, Brasil

rafa.salgad@gmail.com

Marcelo Miná Dias

Universidade Federal de Viçosa, Brasil

minad@uol.com.br

Washington José de Souza

Universidade Federal do Rio Grande do Norte, Brasil

wsufrn@gmail.com
DOI: https://doi.org/10.24215/15155994e137

Redalyc: http://www.redalyc.org/articulo.oa?id=84562590003

Recepción: 07 Febrero 2019

Aprobación: 14 Noviembre 2019

\section{Resumen:}

No tiene

\section{Resumo:}

O artigo analisa a implementação do Programa de Aquisição de Alimentos (PAA) no Brasil, pontuando suas influências na cadeia de produção e comercialização, entraves e potencialidades para o segmento da agricultura familiar. Utiliza-se pesquisa qualitativa, delineada como estudo de caso, por meio da realização de observação direta, análise documental e entrevistas semiestruturadas com agricultores familiares, gestores e entidades beneficiadas. As entrevistas foram submetidas ao software IRAMUTEQ, para análise de conteúdo lexical. Os dados indicaram que além de representar destino singular para o excedente produzido no campo, o PAA constitui-se relevante instrumento de política pública, não apenas pelo potencial de fomento à agricultura familiar, mas, também, pela promoção de segurança alimentar e nutricional a segmentos populacionais em situação de vulnerabilidade socioeconômica. Palavras-Chave: Políticas públicas, Agricultura familiar, Programa de Aquisição de Alimentos, Brasil, Extensão rural, Segurança alimentar e nutricional.

\section{Abstract:}

The article analyzes the implementation of the Food Acquisition Program (PAA) in Brazil, highlighting its influence on the chain of production and commercialization, obstacles and potentialities for the family agriculture segment. We use qualitative research, outlined as a case study, through direct observation, documentary analysis and semi-structured interviews with family farmers, managers and beneficiary entities. The interviews were submitted to IRAMUTEQ software for lexical content analysis. In addition to representing a unique destination for the surplus produced in the field, the PAA constitutes a relevant public policy instrument, not only for the potential of promoting family farming, but also for promoting food and nutritional security for socioeconomic vulnerability.

KeYWORDS: Public policy, Family farming, Food Acquisition Program, Brazil, Rural extension, Food and nutrition security.

\section{INTRODUÇÃo}

O presente artigo tem como objetivo analisar processos de implementação do Programa de Aquisição de Alimentos (PAA) no município de Viçosa/Brasil, pontuando suas influências na cadeia de produção 
e comercialização, entraves e potencialidades para o segmento da agricultura familiar. A agricultura familiar ganhou, em anos recentes, espaço na formulação de políticas públicas no Brasil especialmente pelo reconhecido potencial que detém em termos de legitimação política (Muller, Silva, \& Schneider, 2012), e de produção de matérias-primas e abastecimento alimentar de populações, promovendo desenvolvimento de cidades com perfil econômico predominantemente rural (Becker \& dos Anjos, 2010).

A agricultura familiar, de acordo com dados do Censo Agropecuário de 2006 (IBGE, 2006), produz aproximadamente $70 \%$ dos alimentos destinados ao consumo interno no Brasil. O segmento possui entre $70 \%$ e $90 \%$ dos estabelecimentos rurais e abriga mais da metade do pessoal ocupado no campo (Kageyama, Bergamasco, \& Oliveira, 2013). Mesmo com relevância social na produção de alimentos e na ocupação de mão-de-obra, a agricultura familiar possui participação proporcionalmente menor no valor total da produção e nas receitas da agricultura brasileira, por vezes explicada pela baixa produtividade (Kageyama et al., 2013).

O desempenho econômico do segmento é explicado pela via do restrito investimento do poder público em políticas agrícolas, comerciais e cambiais para a agricultura familiar, em detrimento dos grandes produtores e exportadores de commodities (Buainain et al., 2003; Delgado, 2005). A esfera da produção agrícola é, predominantemente, pautada em um modelo de agricultura intensiva e mecanizada que deixa à margem a parcela de agricultores com capital limitado e dificuldade de acesso a mercados. Tal política do Estado brasileiro, ainda que timidamente, sofreu uma inflexão recente com a implantação de um leque diversificado de políticas públicas voltado para a agricultura familiar (Grisa \& Schneider, 2014). O Programa de Aquisição de Alimentos (PAA), criado em 2003 por meio da Lei Federal n. ${ }^{\circ} 10.696$, ilustra tal movimento estatal.

O PAA cumpre importante papel na institucionalização de compras governamentais de produtos da agricultura familiar (Delgado, Conceição, \& Oliveira, 2006), e representa, nos últimos anos, uma alternativa à comercialização para a agricultura familiar. Além disso, induziu diversificação produtiva e reforço à pluriatividade (Hespanhol, 2013; Salgado \& Dias, 2013), com efeitos importantes na segurança alimentar e no grau de autonomia dos agricultores familiares em suas decisões e ações (Deves \& Rambo, 2013). No entanto, a literatura (Cerqueira, Rocha, \& Coelho, 2006; Grisa, 2010; Salgado \& Dias, 2013) destaca haver limitações quanto à implementação do programa.

Ao tempo que o PAA apresenta inovações institucionais em termos de política pública, ao criar instrumentos de comercialização com garantia de compra, dirigidos especificamente para a agricultura familiar, seus objetivos originários têm alcances limitados e, por essa razão, torna-se pertinente analisar aspectos de operacionalização, desempenho e efetividade. Estudar efeitos da inserção de agricultores familiares em mercados institucionais subsidia futuras decisões de gestores e formuladores de políticas públicas, além de oferecer, a partir de conhecimentos sistematizados, categorias explicativas para se avaliar cenários, gargalos e potencialidades locais, e retroalimentar sistemas técnico-burocráticos.

O interesse por estudos de concepção, implementação, avaliação e monitoramento de políticas públicas tem avançado notadamente nas áreas de Administração Pública, Educação, Saúde e Assistência Social, entre outras, após a inserção do debate do combate à fome e à pobreza extrema no Brasil. Apesar da relevância social que assume, o conjunto das políticas públicas especificas para o meio rural é recente no Brasil, principalmente no âmbito da comercialização de produtos da agricultura familiar (Freitas, 2017; Grisa \& Schneider, 2014; Muller et al., 2012; Schneider, Cruz, \& Matte, 2016). É, pois, com o propósito de contribuir para o debate e a sistematização de resultados de políticas públicas para a agricultura familiar, que este estudo foi realizado.

Para narrar a trajetória e os resultados da pesquisa efetivada entre 2012 e 2013, este texto está estruturado em quatro seções. Após esta introdução, na segunda seção faz-se uma contextualização da agricultura familiar e do PAA, destacando conceitos e estudos relevantes à compreensão do cenário geral que abarca a temática. Posteriormente, são descritos os procedimentos metodológicos, que têm natureza qualitativa. Seguem-se resultados da pesquisa pela via da exposição de resultados, limites e possibilidades do PAA como estratégia de reprodução social, promoção de bem-estar e desenvolvimento local. Como considerações finais, a pesquisa permite indicar que, apesar das limitações, o PAA consiste em uma importante forma de comercialização 
para os agricultores envolvidos, de modo a representar, na maioria dos casos, o destino único do excedente produzido.

\section{Trajetória RECENTE dAS POLÍTICAS PÚBliCAS PARA A AGRICULTURA FAMILIAR No Brasil}

Ações do Estado voltadas para mitigar problemas e dificuldades da agricultura familiar se acentuaram ao longo da década de 1990, encadeada pela valorização crescente do espaço rural brasileiro, diante da persistência da pobreza rural e da percepção sobre a importância sociocultural dos agricultores tradicionais e familiares. Antes, não se percebia a existência de políticas públicas, de abrangência nacional, voltadas à promoção do desenvolvimento rural (Mattei, 2007).

As reivindicações de políticas especificas para o segmento se intensificaram durante os anos 1980, a ponto de ocorrer o reconhecimento da função social da terra na Constituição de 1988, nos seguintes termos:

Art. 186 - A função social é cumprida quando a propriedade rural atende, simultaneamente, segundo critérios e graus de exigência estabelecidos em lei, aos seguintes requisitos:

I - aproveitamento racional e adequado;

II - utilização adequada dos recursos naturais disponíveis e preservação do meio ambien

III - observância das disposições que regulam as relações de trabalho;

IV - exploração que favoreça o bem-estar dos proprietários e dos trabalhadores.

Considerações como aproveitamento racional da terra, utilização adequada dos recursos naturais e exploração favorável ao bem-estar abriram espaço para um viés de atividade agrícola que superou a noção exclusiva de exploração da terra para fins econômico-financeiros, de mercado, de produção de commodities. Tais componentes aparecem como conquistas, e, conforme versam Schneider, Mattei e Cazella (2004), têm origem em constantes manifestações de organizações de movimentos sociais ligados a sindicatos de trabalhadores rurais e agricultores sem-terra, que passaram a reivindicar e lutar para a chamada "reconversão e reestruturação produtiva”. Por meio de avanços na gestão democrática e na participação social permitida pela Constituição Cidadã de 1988, é que várias reinvindicações dos movimentos sociais passaram a compor a agenda governamental e a influenciar a formulação de políticas públicas (Grisa \& Schneider, 2014).

Entre as principais diretrizes reivindicadas pelos movimentos sociais estavam ações voltadas para superar o elevado custo e a escassez de crédito para os agricultores familiares (Simão, Silva, \& Silveira, 2014) e, assim, para atender reinvindicações do segmento, em 1996 foi concebida e implementada a primeira política de abrangência nacional de fortalecimento da agricultura familiar - o Programa Nacional de Fortalecimento da Agricultura Familiar (PRONAF). O PRONAF, na origem (Decreto No 1.946, de 28 de junho de 1996), buscou atender tanto a propósitos de capacidade técnica quanto de inserção da agricultura familiar nos mercados agrícolas, o que representou o reconhecimento e a legitimação do Estado quanto a especificidades e demandas particulares dos agricultores familiares (Gazolla \& Schneider, 2013; Mattei, 2007; Schneider et al., 2004).

Ao dividir o leque das políticas públicas para a agricultura familiar no Brasil em três diferentes gerações, Grisa e Schneider (2014) situam o PRONAF na primeira geração, de viés agrícola e agrário, implementado nos anos 1990 mediante referências à agricultura familiar de forma positiva e relevante quanto a capacidades de financiamento da produção de alimentos e geração de trabalho e renda. Todavia, Andrews (2004) adverte que o sistema de crédito do PRONAF enfrentou dificuldades de implementação junto aos agricultores mais vulneráveis economicamente. Por essa razão, em momento anterior à transição de governos na esfera federal, entre 2001 e 2002, adveio a necessidade de criação de novas intervenções para ampliar os benefícios socioeconômicos aos produtores rurais de menor renda, instituindo processos de comercialização dos produtos (Simão et al., 2014). Tal fato é demarcado, do ponto de vista do marco legal, por instrumentos como o Programa Garantia Safra (Lei No 10.420, de 10 de abril de 2002), o Programa de Habitação Rural 
(PNHR, por meio da Lei no 11.124/2005), o Programa Desenvolvimento Sustentável de Territórios Rurais (Pronat, via Resolução No 37 do Condraf, de 03 de dezembro de 2003), e o Programa Fome Zero (Medida Provisória 103, de $1^{\circ}$ de janeiro de 2003). Estas são, pois, medidas que integram a segunda geração de políticas públicas para a agricultura familiar, caracterizadas como de transição, de caráter socioassistencial, com o objetivo central de combater a pobreza e reduzir desigualdades no meio rural (Grisa \& Schneider, 2014).

Apesar dos avanços logrados no ambiente institucional, acadêmico e ideológico até o início dos anos 2000 - marcados pela conquista da função social da terra na Constituição de 1988, pela criação do PRONAF e pelas políticas socioassistenciais -, as demandas de garantia de renda, acesso a mercados e garantia de preço para a produção familiar só seriam qualificadas na terceira geração de políticas com a criação do Programa de Aquisição de Alimentos (PAA), a partir de 2003, no âmbito do Fome Zero e de estratégias do Governo Lula (Graziano da Silva, Del Grossi, \& França, 2012; Sambuichi, Galindo, Oliveira, \& Moura, 2014). A criação do PAA foi elemento fundamental no surgimento da terceira geração de políticas públicas para a agricultura familiar, pois, abriu uma "janela de oportunidades" (Kingdon, 2014, p. 165) e gerou aprendizados para a construção de novas ações (Grisa \& Schneider, 2014).

As políticas da terceira geração fortaleceram os propósitos de legitimação política e o reconhecimento social da importância da agricultura familiar na sociedade brasileira (Muller et al., 2012) avançando para além da intervenção em processos produtivos uma vez considerando a multidimensionalidade que afeta a vida e a produção na agricultura familiar (Freitas, Freitas, \& Dias, 2012). Desse modo, contribuíram tanto para resgatar, manter e fortalecer a produção de produtos agrícolas tradicionais, por meio do desenvolvimento de mercados locais e regionais (Dias, Nunes, Torres, \& Torres, 2013), quanto para garantir alimentação a segmentos populacionais, rurais e urbanos - beneficiários de políticas públicas - em situação de insegurança alimentar.

Como medida preliminar da $3^{\text {a }}$ geração, o PAA foi considerado iniciativa inovadora em termos de objetivos, forma de implantação, sistema de gestão e marco legal, uma vez que rompeu com tendências habituais, com modelos já estabelecidos (Delgado et al., 2006; Müller, 2007; Porto et al., 2014). O Programa tem como objetivo auxiliar a comercialização dos produtos oriundos da agricultura familiar, mediada pelo propósito da segurança alimentar e nutricional via acesso a alimentos em quantidade, qualidade e regularidade, adequados ao atendimento das demandas das famílias rurais. A ideia central do PAA é a promoção de renda local e a segurança alimentar e nutricional reunindo produção e consumo (Schmitt, 2014). Com o Estado como um dos principais atores na esfera da compra (comercialização), o Programa estabelece ligação entre agricultores familiares (produtores) e pessoas em vulnerabilidade nutricional ou cuja responsabilidade alimentar recaia sobre o setor público (consumidores), a exemplo de unidades escolares e da assistência social (Mielitz, 2014).

A estratégia do PAA pode ser considerada iniciativa inovadora e recente na história do País (Dias et al., 2013) uma vez que inovou ao articular iniciativas de política agrícola com ações de segurança alimentar e nutricional (SAN) da população (Grisa, 2012), permitindo a emergência e o fortalecimento de mercados institucionais para a agricultura familiar. Promover o acesso à alimentação para população vulnerável comprando alimentos da agricultura familiar - era algo até então inexistente em todo o mundo, pois, as iniciativas existentes se centravam em projetos pilotos, desarticulados e sem escala (Campos \& Bianchini, 2014). Antes do PAA houve apenas iniciativas isoladas de compra de produtos da agricultura familiar no âmbito da alimentação escolar (Carvalho, 2009; Schimitt \& Guimarães, 2008).

Em termos operacionais, o PAA possui seis modalidades: Compra Direta da Agricultura Familiar, Compra com Doação Simultânea (PAA/CDS), Apoio à Formação de Estoques pela Agricultura Familiar, Incentivo à Produção e ao Consumo de Leite - PAA Leite, Compra Institucional, e, mais recentemente, Aquisição de Sementes. Cada modalidade responde a objetos distintos, tais como formação de estoques de alimentos para atendimento a situações emergenciais, apoio à formação de estoques pelos próprios agricultores, 
complementação do abastecimento de uma ampla rede de equipamentos públicos de alimentação e nutrição, aquisição de sementes crioulas, entre outros (Campos \& Bianchini, 2014).

QUADRO 1

Síntese do marco legal das 3 gerações de políticas públicas para a agricultura familiar a partir de 1988

\begin{tabular}{|c|c|c|c|}
\hline Gerações & Período & $\begin{array}{l}\text { Natureza da política } \\
\text { pública }\end{array}$ & Políticas Públicas e Marco legal \\
\hline 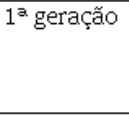 & $1988 \ldots$ & $\begin{array}{l}\text { Cunho agrário e agrícola } \\
\text { com foco no financiamento } \\
\text { da produção e na geraçấo de } \\
\text { trabalho e renda. }\end{array}$ & $\begin{array}{l}\text { Lei No } 8.171 \text {, de 1991, Arts. 59, } 66 \text { e 65: Proagro Mais (Seguro da Agricultura Familiar } \\
\text { - SEAF); Decreto } \text { n }^{\circ} 1.946 \text {, de 1996: PRONAF; Decreto No 5.996, de 2006: Programa } \\
\text { de Garantia de Preços para a Agricultura Familiar (PGPAF); Assistência Técnica e } \\
\text { Extensão Rural; Assentamentos de reforma agrária. }\end{array}$ \\
\hline $2^{\text {a }}$ geração & 1997. & $\begin{array}{l}\text { Foco socioassistencial } \\
\text { baseado no combate à } \\
\text { pobreza e na redução de } \\
\text { desigualdades. }\end{array}$ & $\begin{array}{l}\text { Pronaf infraestrutura e Serviços Municipais; Lei } N^{\circ} 10.420 \text {, de } 10 \text { de abril de } 2002 \text { : } \\
\text { Garantia Safra. Resolução } N^{\circ} 37 \text { do Condraf, de 2003: Programa Desenvolvimento } \\
\text { Sustentável de Territórios Rurais; Lei } n^{\circ} 11.124 / 2005 \text { : Programa Nacional de } \\
\text { Habitação Rural; Medida Provisória } 103 \text {, de } 1^{\circ} \text { de janeiro de } 2003 \text { : Fome Zero Lei } N^{\circ} \\
10.836 \text {, de 2004: Bolsa Família. }\end{array}$ \\
\hline $3^{a}$ geraçẫo & $2003 \ldots$ & $\begin{array}{l}\text { Orientação para a garantia } \\
\text { de mercados, segurança } \\
\text { alimentar e nutricional e } \\
\text { Sustentabilidade. }\end{array}$ & $\begin{array}{l}\text { Lei n 10.696, de 2003: Programa de Aquisição de Alimentos; Lei n } 11.47 \text {, de 2009: } \\
\text { Programa Nacional de Alimentação Escolar; Decreto n } 79 \text {, de 1966: Políticas } \\
\text { Garantidoras de Preços Mínimos; Agroindústria, selos e certificações; Comercialização } \\
\text { de produtos da biodiversidade. }\end{array}$ \\
\hline
\end{tabular}

Fonte: Elaboração própria com base em Grisa e Schneider (2014)

Na modalidade Compra com Doação Simultânea (CDS), cooperativa, associação e agricultores familiares individuais podem vender produtos para os governos Federal (via CONAB), estadual e municipal. $\mathrm{Na}$ execução via CONAB, modalidade acessada pelos agricultores de Viçosa/MG, os produtos adquiridos são entregues diretamente aos beneficiários finais, consumidores. Os consumidores podem se encontrar em equipamentos públicos de alimentação e nutrição (restaurantes populares, cozinhas comunitárias, unidades de apoio à distribuição de alimentos da agricultura familiar, bancos de alimentos e mercados populares), ou em unidades da rede socioassistencial, governamental ou não-governamental, de atendimento a populações em situação de Insegurança alimentar e nutricional (MDS, 2018).

Para participar do fornecimento de alimentos por meio do PAA/CDS, a organização de agricultores interessada precisa elaborar um plano de trabalho e apresentar uma proposta de participação (CONAB, 2017). Nesta fase é importante o envolvimento de outros atores sociais, como extensionistas públicos, potenciais beneficiários, e membros dos conselhos locais de alimentação para o planejamento e a execução bem-sucedida do PAA (Botelho Filho et al., 2007; Müller, Fialho, \& Schneider, 2007). Aprovada a proposta de participação, a organização emite uma Cédula de Produto Rural (CPR-Doação) e passa a fornecer alimentos às entidades conforme definido na proposta. Após a confirmação da entrega dos produtos, a Conab disponibiliza os recursos pactuados na conta da organização, que realiza o pagamento aos agricultores.

Além do fortalecimento da agricultura familiar, estudos no âmbito do PAA têm evidenciado a sua importância para a promoção de inclusão social no campo e valorização dos produtores locais (Becker \& dos Anjos, 2010), com efeitos no aumento, na diversificação e na qualificação da produção. Segundo Müller, Fialho e Schneider (2007), o PAA tem auxiliado, ainda, agricultores no acesso a novos mercados. Por outro lado, ao avaliarem a repercussão do Programa em entidades beneficiárias e consumidores, Zimmermann e Ferreira (2008), Vieira e Del Grossi (2010) e Becker e Sacco dos Anjos (2010) apontam melhorias na qualidade da alimentação servida. O presente estudo caminha, pois, nesse viés de evidenciação de resultados do PAA, pautando processos de implementação a partir de estudo de caso no município de Viçosa no estado de Minas Gerais/Brasil, pontuando suas influências na cadeia de produção e comercialização, entraves e potencialidades para o segmento da agricultura familiar.

O município de Viçosa faz parte da Microrregião Geográfica de Viçosa, situada na mesorregião Zona da Mata de Minas Gerais. O município possui 299 km2 e exerce maior centralidade na rede urbana regional em virtude de concentrar a maior variedade de equipamentos, infraestrutura e serviços urbanos. A microrregião é 
formada por 19 municípios de pequeno porte e a economia detém baixa expressividade industrial, assumindo significativa relevância, em termos de absorção de pessoal e de arrecadação de impostos, as atividades de comércio e prestação de serviços. O setor agropecuário tem igualmente importância econômica considerando que demandas da população rural - diretas (compras de insumos e equipamentos, consertos de máquinas e implementos, comercialização da produção, acesso ao crédito rural etc.) e indiretas (aquisição de gêneros alimentícios, de limpeza e higiene pessoal; eletrodomésticos, medicamentos etc.) - têm efeitos no comércio e no setor de prestação de serviços. A população rural do município de Viçosa, é pertinente ressaltar, totaliza 81.611 habitantes, representando $37 \%$ do total de 221.585 habitantes da microrregião (IBGE, 2011).

Em Viçosa, de acordo com dados do Censo Agropecuário (2006), havia 358 estabelecimentos da agricultura familiar, correspondendo a $79 \%$ do total, ocupando $64 \%$ da área total do município e representando $40 \%$ do valor bruto da produção total. Ainda de acordo com o censo, 202 estabelecimentos (56\%) estavam classificados como "quase sem renda" ou "renda baixa". Dos 358 estabelecimentos, 121 (34 \%) detinham status "não integrados" a mercados. Esse dado evidencia situação de insegurança econômica em considerável número de estabelecimentos da agricultura familiar no município de Viçosa-MG, atentando para a necessidade de políticas públicas de compras governamentais, a exemplo do PAA, na reprodução social e no fortalecimento do segmento.

\section{Procedimentos Metodológicos}

Esta pesquisa tem natureza descritiva com abordagem qualitativa (Gil, 2017). O escopo descritivo desta pesquisa encontra-se delimitado por incursões a campo para traçar características dos grupos envolvidos e suas percepções, bem como do contexto em que a política pública em pauta estava sendo implementada. Trata-se, quanto aos meios de investigação, de estudo de caso Gil (2017).

Os agricultores familiares de Viçosa/MG acessaram o Programa de Aquisição de Alimentos por meio da modalidade Compra com Doação Simultânea executada pela CONAB. O primeiro projeto ao PAA/ CDS em Viçosa/MG foi apresentado pela Associação de Desenvolvimento Comunitário Desejo de Vencer da Região de Vista Alegre (ACDCV) em 2006. Nos anos 2007 e 2009 a ACDCV aprovou novamente, acompanhada da Associação de Moradores do Córrego São Francisco (AMCSF) em projetos aprovados separadamente. Em 2010, apenas a AMCSF acessou o programa beneficiando doze entidades consumidoras. Em 2012, apresentaram propostas a ACDCV, a AMCSF e a Associação Viçosa de Apicultores (AVA). Diante desse desempenho do PAA/CDS em Viçosa/MG até 2012, ano da coleta de dados da presente pesquisa, foram então selecionados nove agricultores, proponentes pela AMCSF, por ter sido tal organização a única a apresentar proposta ao PAA/CDS em chamadas seguidas da Companhia Nacional de Abastecimento (CONAB) entre 2007 e 2012. Dos nove membros proponentes pela AMCSF em 2010, quatro não executaram, restando cinco agricultores fornecedores, e, nessa condição, informantes principais desta pesquisa.

Para revelar, pois, características do processo de implementação do PAA tomando como base o município de Viçosa/MG, a investigação foi realizada junto a famílias atendidas, localizadas na comunidade rural Córrego São Francisco (Juquinha de Paula), pertencentes à Associação de Moradores do Córrego São Francisco (AMCSF). A pesquisa envolveu, também, atores responsáveis pela implementação do PAA, sumarizados no Quadro 2. No total, 11 informantes foram considerados para a coleta de dados, que ocorreu por meio de entrevista semiestruturada. Os dados coletados possibilitaram um exercício de triangulação de informações entre atores do corpo técnico-burocrático do PAA, consumidores (beneficiários) e agricultores familiares. 
QUADRO 2

Informantes na coleta de dados primários

\begin{tabular}{|l|l|l|l|}
\hline Instituição & Cargo & Papel & Total \\
\hline EMATER - MG & Técnico & $\begin{array}{l}\text { Apoio local na elaboração e } \\
\text { implementação }\end{array}$ & 1 \\
\hline Secretária de Agricultura & $\begin{array}{l}\text { Secretário } \\
\text { Municipal }\end{array}$ & $\begin{array}{l}\text { Apoio indireto na } \\
\text { implementação }\end{array}$ & 1 \\
\hline APOV; Rebusca & Presidente & $\begin{array}{l}\text { Entidades socioassistenciais } \\
\text { receptoras de alimentos }\end{array}$ & 2 \\
\hline $\begin{array}{l}\text { Conselho Municipal de } \\
\text { Segurança Alimentar e } \\
\text { Nutricional }\end{array}$ & Presidente & Controle social do Programa & 1 \\
\hline Associação dos agricultores & Presidente & $\begin{array}{l}\text { Mobilização dos agricultores } \\
\text { e suporte às entregas }\end{array}$ & 1 \\
\hline Agricultores & $\begin{array}{l}\text { Beneficiários } \\
\text { fornecedores }\end{array}$ & $\begin{array}{l}\text { Fornecedores de produtos ao } \\
\text { PAA }\end{array}$ & 5 \\
\hline Total de informantes & \multicolumn{3}{|l}{} \\
\hline
\end{tabular}

Fonte: Elaboração pelos autores (2019).

As principais questões levantadas junto aos agricultores da AMCSF captaram aspectos positivos, limitações, tanto operacionais quanto institucionais, dificuldades enfrentadas e expectativas quando à continuidade do programa. Análise documental permeou o estudo com o objetivo de identificar número de agricultores cadastrados, entidades consumidoras cadastradas e produtos fornecidos. Para isso, foram analisados documentos disponibilizados tanto pela organização dos agricultores pesquisada quanto pela Empresa de Assistência Técnica e Extensão Rural do Estado de Minas Gerais (EMATER-MG).

As informações coletadas na entrevista individual com os cinco agricultores familiares foram submetidas a tratamento no software Interface de R pour les Analyses Muldimensoionnelles de Textes et de Questionnaires (IRAMUTEQ), com o propósito de definir categorias analíticas a partir de vivências do segmento intermediário na execução do PAA - qual seja, o agricultor familiar que atua na política pública fornecendo produtos para os beneficiários finais (consumidores).

A análise lexical por meio do IRAMUTEQ supera a dicotomia entre dados quantitativos e informações qualitativas, uma vez que permite empregar cálculos estatísticos em textos tomando como base frequências de vocábulos, e, por vezes, tratando a relação de posição de cada palavra no texto (Lahlou, 2012). A análise lexical aqui procedida ocorreu em três etapas: pré-análise, exploração do material e interpretação dos resultados obtidos. O processamento no IRAMUTEQ - é pertinente destacar - contemplou exclusivamente os textos transcritos do material coletado junto aos agricultores, considerando a diversidade das questóes e dos conteúdos abordados junto aos outros dois segmentos envolvidos na execução do PAA - órgão público executor e beneficiário final.

Seguindo orientações do tutorial do IRAMUTEQ (Camargo \& Justo, 2013), o corpus foi constituído pela reunião dos textos transcritos das cinco entrevistas, gerando um único documento para processamento. O processamento gerou 9.618 ocorrências de palavras, apresentadas em 983 formas distintas. Foi então empregado o critério de ponto de corte, para a inclusão no dendograma, o dobro da frequência média, neste caso, $n=6$. Tal procedimento é sugerido por Camargo e Justo (2013), e tem o propósito de ilustrar as relações entre as classes. O processamento do corpus deu origem a 282 segmentos de texto (ST). Tais segmentos correspondem aos cortes que o software realizou durante o processamento, com aproveitamento de 221 STs, o que corresponde a 78,37 \% de retenção. Tal percentual de retenção configura corpus representativo, considerando que o aproveitamento deve ser de, no mínimo, 75 \% dos STs (Camargo \& Justo, 2013). Constatada a retenção em percentual satisfatório, a análise prosseguiu para a Classificação Hierárquica Descendente (CHD), que tem como propósito obter classes de ST que, ao mesmo tempo, apresentam 
vocabulário semelhante entre si, e vocabulário diferente dos segmentos das outras classes (Camargo \& Justo, 2013).

Categorias previamente apontadas pela literatura (Alves, Vieira, Silva, \& Ferreira, 2011; Cerqueira et al., 2006; Hespanhol, 2013; Vieira \& Del Grossi, 2010) puderam ser estratificadas a partir dos resultados originários do processamento do software. Considerando as categorias acatadas na literatura operacionalização, caracterização e avaliação do programa - os resultados trazem a seguinte configuração: em caracterização emergem as categorias mercados institucionais e produtos comercializados; em avaliação do programa aparecem relação entre zona rural e cidade, benefícios/resultados do programa e papel da extensão rural. A categoria operacionalização não surgiu na presente análise, o que pode ser explicado pelo fato de que o órgão executor do PAA/CDS é a Companhia Nacional de Abastecimento (CONAB), estando os informantes desta pesquisa assumindo papel de intermediação.

\section{O PAA Compra com Doação Simultânea (CDS) no município de Viçosa-MG}

No caso aqui estudado, o projeto do PAA/CDS envolveu nove agricultores, com um investimento total de $\mathrm{R}$ $\$ 30.018,71$. O valor médio para cada agricultor foi de $\mathrm{R} \$ 3.335,41$. Os produtos adquiridos foram entregues para doze entidades do próprio município, contemplando um total de 1.578 pessoas atendidas (Tabela 1). Entre as entidades havia a presença de hospitais filantrópicos, creches municipais e filantrópicas, entre outras. Estas entidades atendiam crianças, idosos, dependentes químicos e famílias carentes, beneficiando público diversificado e de alto risco de vulnerabilidade social e de segurança alimentar.

TABELA 1

Entidades beneficiárias e número de beneficiados do PAA em Viçosa

\begin{tabular}{l|l}
\hline Entidades & $\begin{array}{l}\text { Número de } \\
\text { Pessoas Atendidas }\end{array}$ \\
\hline Centro Educação Infantil Pingo de Luz & 36 \\
\hline Associação Beneficente Santa Clara (ABESC) & 83 \\
\hline Conselho Central de Viçosa da Sociedade Săo Vicente de Paulo & 1000 \\
\hline Rebusca AÇão Social Evangélica Viçosense & 325 \\
\hline ASsociação Assistencial e Promocional da Pastoral da Oração de & 134 \\
Viçosa (APOV) & 1578 \\
\hline Total & \\
\hline
\end{tabular}

Fonte: Proposta de Participação - Doação Simultânea, 2010.

Os produtos do PAA eram entregues semanalmente, toda terça feira. Em entrevista com presidentes da APOV e Rebusca e com a presidente do CONSEA municipal não foi relatado atrasos no cronograma de entrega. Entretanto, Cordeiro (2007) lembra que as perdas ocasionadas por seca ou outras adversidades climáticas podem comprometer o cumprimento das entregas previstas nos projetos.

Vieira e Del Grossi (2010) assinalam a falta de exigência do cumprimento de um cronograma de entrega como sendo uma dificuldade do programa, ressaltando a necessidade de incentivo ao planejamento e ao gerenciamento das atividades. É necessário enfatizar a importância do planejamento da produção e da entrega, qualidade dos produtos, regularidade da oferta e volume de produção, principais dificuldades enfrentadas pela agricultura familiar, ou seja, representam fatores condicionantes para o acesso aos mercados.

De acordo com as regulamentações do programa, a proposta de participação deve apresentar o cronograma e o local onde será realizada a entrega dos produtos (CONAB, 2017). O transporte dos produtos do local de produção até o de consumo caracteriza-se como mais uma importante dificuldade para a execução do programa (Botelho Filho et al., 2007; Cordeiro, 2007; Grisa, Schmitt, Mattei, Maluf, \& Leite, 2011; Vieira \& Del Grossi, 2010; Zimmermann \& Ferreira, 2008). Basicamente, as grandes distâncias, as precárias condições 
das estradas, a falta de veículos, e o elevado custo acabam por limitar a participação e execução do PAA (Grisa et al., 2011). No caso estudado, a prefeitura do município oferecia apoio logístico buscando a produção na comunidade rural. As entidades beneficiadas buscavam os produtos no local onde funcionava a feira municipal. As organizações proponentes devem buscar o apoio das prefeituras desde a elaboração da proposta, uma vez que a parceria e articulação com o poder público para operacionalização do PAA é um dos fatores condicionantes de seu sucesso (Vieira \& Del Grossi, 2010).

\section{CARACTERIZAÇÃo dos AGRICULTORES BENEFiCIÁRIOS}

Verificou-se, por meio das entrevistas, que todos os agricultores fornecedores eram proprietários rurais; a extensão territorial das propriedades variava de 02 a 22 hectares. A utilização de mão-de-obra é praticamente familiar; a maioria utiliza terceiros diaristas na época de plantio e colheita; apenas um agricultor não empregava nenhuma mão-de-obra contratada.

Em termos sociais, foram levantadas informações sobre a faixa etária, escolaridade e número de filhos dependentes dos agricultores titulares PAA no ano de 2010. Em relação ao nível escolar dos agricultores, observou-se que a maioria não concluiu o ensino fundamental. Todos são casados e possuem filhos dependentes. A idade média dos produtores era de 45,6 anos. Estes dados vão ao encontro do relatado porGodoy, Perez, Wizniewiski, Guedes e Moraes (2010), ao comentar que a faixa etária preponderante da população rural é de mais de 40 anos, pois a juventude rural, sem atrativos no campo, migra para as cidades.

Buscou-se verificar a presença de rendas não agrícolas entre as famílias beneficiadas pelo programa. Foi constatado que somente um agricultor possuía renda proveniente exclusivamente da exploração agrícola. Dentre as demais, observou-se que três agricultores são beneficiários do Programa Bolsa Família e que um trabalha em atividade urbana. A aposentadoria foi citada por um agricultor. Percebeu-se que uma parcela consistente de famílias beneficiárias do PAA (4/5) declarou ser também beneficiária de algum tipo de benefício social dos governos federal, estadual ou municipal, tais como Bolsa Família, Aposentadoria, Família Acolhedora, Mecanização Agrícola e PRONAF, indicando uma tendência à agregação de políticas públicas no município.

A principal fonte de renda dos informantes é a agricultura, cultivando principalmente hortaliças, leguminosas e frutas. Os cinco informaram, ainda, que criam animais, aves e suínos para subsistência e vacas leiteiras, utilizadas como uma poupança para uma eventual necessidade, como cobrir custos de dívidas. A integração de atividades agropecuárias na propriedade resulta na produção diversificada no tempo e no espaço, aumentando tanto a eficiência do sistema agrícola do ponto de vista ecológico, quanto a flexibilidade econômica da unidade produtiva face às incertezas decorrentes das flutuações dos preços agrícolas e das intempéries do tempo. Há diversidade agrícola, o que permite o aproveitamento cíclico de subprodutos animais ou vegetais caracterizando pluriatividade, dimensão importante na forma de trabalho contemporânea no meio rural, pois, além de aumentar a renda, permite ao agricultor estabilizar e diversificar as fontes de ganhos, sobretudo, por meio do acesso a rendas não agrícolas (Schneider, Conterato, Koppe, \& Silva, 2006).

\section{Operacionalização do Programa de AQuisição de Alimentos - CDS pela Associação dos Moradores do Córrego São Francisco}

A Figura 1 (abaixo) sintetiza, em dendograma, categorias geradas pelo IRAMUTEQ no processamento de informações relacionadas à execução do PAA/CDS a partir do papel assumido pelo ator intermediário, qual seja, o agricultor familiar que submete proposta à CONAB para entrega de produtos a organizações públicas governamentais e não-governamentais demandantes de alimentos no seu funcionamento, a exemplo 
de creches, asilos, hospitais e restaurantes populares. São cinco categorias que se estruturam em dois eixos a partir de classes assim denominadas: no primeiro eixo, Caracterização, encontram-se as classes 1 e 2 , respectivamente denominadas de Mercados institucionais (18,6 \%) e Produtos comercializados (19,9\%); no segundo, Avaliação do Programa, estão as classes 3, 4 e 5 relativas, respectivamente, às categorias Relação entre zona rural e cidade (19,9\%), Benefícios/resultados do Programa (18,6 \%) e Papel da extensão rural (23,1 \%).

Na Classe 1, Mercados institucionais, os agricultores ressaltam a importância do PAA como mercado garantido para a produção da agricultura familiar. Forneceram ao programa porque veem vantagens em comercializar o que produzem, de imediato, sem intermediários e atravessadores. A garantia de mercado e a melhoria da renda os incentivou. A ausência de exigência do programa quanto à qualidade do produto, definida pela aparência, é motivo de comemoração, e, por essa razão, o Agricultor 1 destaca:

Não importa se era grande ou pequena [o tamanho do produto], especificação não tinha. Ai, era um ótimo negócio, porque se você for classificar demais igual manda pro CEASA fica cheio de problema, manda mercadoria ruim que não tem preço. Você manda boa só, você não consegue. A CONAB não, pegava produto de primeira, segunda e terceira com o mesmo valor, o valor mínimo, mas bom (Agricultor 1, 2012).

\section{FIGURA 1}

Categorias analíticas geradas

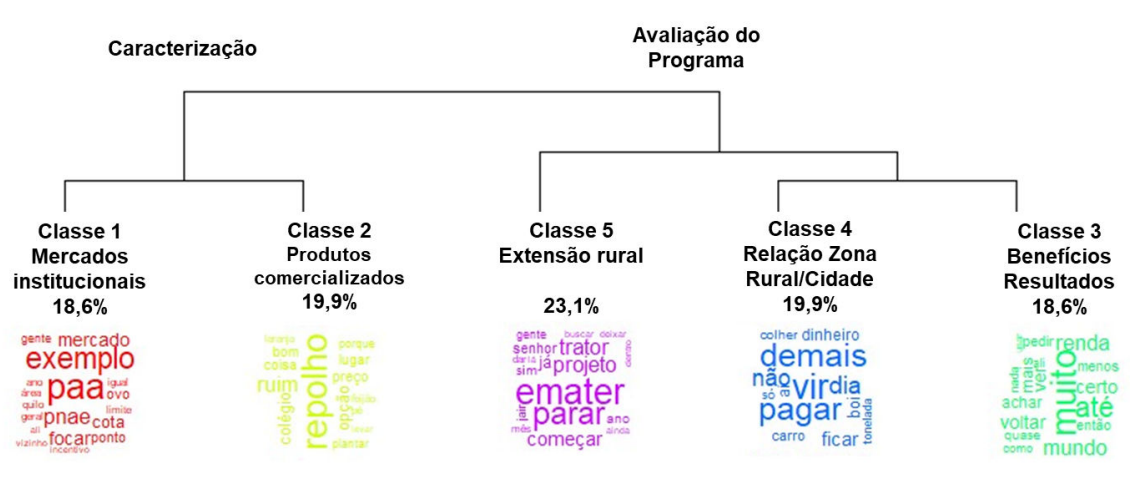

Fonte: software IRAMUTEQ, dados da pesquisa (2018).

Apesar de apontado como fator positivo, a não especificação pode incentivar os agricultores a fornecer produtos com baixa qualidade, e, assim, em contraposição, outro informante alerta: "Tudo que produzia, nós estávamos levando para lá - chuchu, mandioca, feijão, o que tivesse. Então acho que aquilo ali era pouco, tinha que ter maior exigência, porque tinha gente levando mercadoria muito ruim" (AGRICULTOR 4, 2012).

O controle de qualidade dos produtos perpassa pela atuação de outros atores. O representante da APOV mencionou que o controle de qualidade era realizado por meio de conversas com os agricultores fornecedores e na instituição era a nutricionista quem orientava e fazia o controle. Sousa, Silva, Azevedo e Ramos (2015) destacam a importância da participação de diferentes atores como nutricionistas, merendeiras, professores, gestores, agricultores e conselheiros no acompanhamento do programa. A articulação entre os agentes locais é fator fundamental para o planejamento e execução das políticas de compra institucional, especialmente pela atuação limitada e incipiente da gestão pública municipal e do controle social. Além disso, deve-se ressaltar que a aproximação da produção com o consumo pode auxiliar no processo de elaboração dos cardápios, possibilitando a inclusão de alimentos já produzidos pela agricultura familiar.

Em que pese o fato de atuarem no PAA/CDS e ser este o objeto da pesquisa, os agricultores fizeram menção ao Programa Nacional de Alimentação Escolar (PNAE), marcando pontos fortes de outro mercado institucional de aquisição de alimentos da agricultura familiar de iniciativa do Governo Federal. Esse fato conduz ao entendimento de que os agricultores percebem o PAA e o PNAE como políticas públicas que exercem papel semelhante no que se refere ao fortalecimento da agricultura familiar. Nesse sentido, é válido registrar que a Lei n. ${ }^{\circ} 11.947$, de 16 de junho de 2009, determinou que o percentual mínimo $30 \%$, do valor 
repassado a estados, municípios e Distrito Federal pelo Fundo Nacional de Desenvolvimento da Educação (FNDE) para o Programa Nacional de Alimentação Escolar (PNAE), deve ser utilizado na compra de gêneros alimentícios diretamente da agricultura familiar e do empreendedor familiar rural, ou de suas organizações, priorizando-se os assentamentos da reforma agrária, as comunidades tradicionais indígenas e as comunidades quilombolas.

A Classe 2 se relaciona aos produtos comercializados por meio do PAA/CDS, comumente chamado pelos agricultores de "projeto Conab", pelo fato de se tratar de contrato firmado entre associações de produtores e aquele órgão do Governo Federal. As principais culturas comercializadas pelos agricultores pesquisados são mandioca, frutas e olerícolas, estas representadas, sobretudo, por couve-flor, alface, cebolinha e cheiro verde. Foram comercializados, ainda, produtos originários da agroindustrialização, representados por fubá de milho e canjica de milho. Tais produtos são abundantes na região e, em virtude da abundância na quantidade ofertada, trazem dois impasses ao agricultor familiar: dificuldades para comercializa-los juntos aos mercados convencionais em função da concorrência entre produtores melhor estruturados e preço em níveis insatisfatórios, considerando a restritiva capacidade em competir com grandes fornecedores.

A diversificada gama de produtos comercializados é avaliada positivamente pelos beneficiários consumidores. Segundo representantes da APOV e Rebusca, os consumidores dos alimentos adquiridos por intermédio do PAA avaliam positivamente a mudança na composição de sua dieta, destacando aspectos quantitativos e qualitativos, como maior diversidade de alimentos (frutas e legumes), fato esse que teria influenciado na criação de novos hábitos alimentares.

A Classe 5 atenta para a relevância e o papel do serviço público de assistência técnica e extensão rural (ATER) no resultado do programa. A EMATER apareceu assumindo papel relevante como órgão executivo auxiliar, atuando diretamente na orientação dos agricultores e na elaboração dos projetos para acessar o PAA. Os agricultores familiares recordam a relevância de tal órgão de ATER assim se pronunciando:

Eles reúnem com a gente sempre. Eles pegaram e divulgaram com a gente, orientaram a gente a fundar a associação (...) através da associação a gente vendia. Criamos a associação e através da Emater, aí, a gente entrou no PAA, através da assistência da Emater (Agricultor 3, 2012).

Essa adequação [da produção às demandas das chamadas do programa] não foi difícil não, porque o pessoal da Emater nos orientou; eles orientaram a gente a manter o mesmo que a gente já trabalhava (Agricultor 3, 2012).

Fica revelada, assim, a relevância que assumem os serviços de ATER no tocante ao acesso ao conhecimento e à orientação na produção, e, principalmente, na elaboração das propostas. De outra forma, é factível assumir que tais produtores rurais não acessariam o programa. No caso em pauta, o serviço de ATER assumiu papel relevante antes mesmo do interesse imediato de promover acesso ao PAA, considerando que aquele órgão público foi responsável por motivar os agricultores à criação da associação, conforme lembrou o Agricultor 3. Os agricultores também afirmam que, por meio da assistência técnica da EMATER, passaram a utilizar novas técnicas no sistema produtivo, como a troca do uso de agrotóxico pelo uso de adubação química e orgânica.

Observa-se que estes resultados vão de encontro ao relatado por Simão e Silva (2014) em que o extensionista atua sob dois enfoques, o informativo e o executivo. No âmbito informativo, é o extensionista quem leva ao conhecimento dos atores interessados a existência e o modo de atuação do programa. $\mathrm{Na}$ fase executiva, o extensionista atua diretamente na elaboração dos procedimentos burocráticos necessários ao envio da documentação para a unidade executora (CONAB) e na efetiva operacionalização do programa.

Constatou-se neste estudo, tal como evidenciado por Paula, Kamimura e Silva (2014), que a assistência técnica pública assume papel relevante tanto na formação para a gestão de processos produtivos e na elaboração de projetos para mercados institucionais, quanto no incentivo à constituição de cooperativas e associações. Para conseguir acessar os recursos do PAA entra em cena a figura do agente de assistência técnica e extensão rural (ATER) que, majoritariamente, passa a ser o responsável por elaborar e submeter as propostas às entidades públicas via associação ou cooperativas. Essa colaboração é necessária, entre outros aspectos, 
em virtude de exigências burocráticas estranhas ao mundo rural. Desse modo, frequentemente o agente de ATER assume a função de elo entre o produtor, sua organização coletiva, e a organização compradora ou consumidora, cumprindo assim papel de agente de política pública, distinto do convencional, de promoção do desenvolvimento rural (Silva, Ferreira, \& Amodeo, 2014).

A Classe 4 está relacionada à relação entre o Programa de Aquisição de Alimentos, a zona rural e a cidade. Segundo os relatos dos agricultores, há uma série de limitações estruturais que dificultam ou inviabilizam o fornecimento de alimentos à cidade, com destaque para estradas precárias, elevado custo logístico e ausência de internet, o que dificulta o processo de prestação de contas à CONAB, conforme relatos abaixo.

A estrada precisa melhorar mais, a nossa estrada ela já melhorou bastante diante do passado, mas ela precisa melhorar mais, colocar cascalhamento, melhora a drenagem (Agricultor 3).

A entrega é meio complicada para gente, toma um tempinho da gente, tem que levar e distribuir (...). A vontade é que se nosso prefeito, no caso, pedisse para arrumar um jeito de buscar na zona rural, que tivesse um ponto, um ponto fixo pra gente trazer, deixar na casa de alguém e o prefeito mandar buscar (Agricultor 1).

A prestação de contas também é muito rigorosa, tem muita dificuldade na prestação de contas, por não termos muito conhecimento e depender de certo conhecimento para você fazer. Sugiro menos burocracia, tanto na aprovação do projeto, como na questão de prestação de contas, é para facilitar para o produtor, nem todo produtor tem acesso à internet ou a prestação de contas (Agricultor 2).

A Classe 4 expõe os principais resultados/benefícios do PAA/CDS. O fato de promover garantia de venda foi a vantagem mais mencionada pelos agricultores e a fala do Agricultor 3 é ilustrativa nesse sentido: "Eu vou produzir uma mandioca ali e vou saber que não vou perder ela, qualquer coisa que eu vou produzir no meu dia-a-dia eu sei que tenho um mercado garantido para ela" (Agricultor 3, 2012). Outros pontos mencionados foram: a garantia do preço, mesmo que mínimo, a assessoria recebida para melhoria na qualidade dos produtos (por intermédio da assistência da EMATER) e fixação do produtor no campo.

No que concerne aos efeitos do programa sobre a renda, os agricultores apontam o PAA como complemento de renda. Por outro lado, quando questionados a respeito da possibilidade do término do programa, os entrevistados manifestam a importância de sua continuidade para a manutenção da propriedade rural e a realização de novos investimentos. Por intermédio da melhora na renda puderam eles adquirir equipamentos, como roçadeira e trator, investindo na propriedade. O Agricultor 1 afirma que "Com o PAA cheguei a comprar um trator. $O$ dinheiro que entra aqui paga a prestação lá, que é uma vez ao ano". Para o Agricultor 2, ao fornecer ao PAA, "passamos a usar outros equipamentos, e, hoje, a gente usa muito a roçadeira; o trator a gente usa mais para mexer com o solo".

Quando perguntados acerca do efeito do PAA sobre o preço dos produtos agrícolas na região, os produtores relataram que os valores contratados com a CONAB não influenciam o mercado local. Inclusive, registram que no contrato implementado com a $\mathrm{CONAB}$ os preços de alguns produtos estiveram em nível de $50 \%$ inferior ao preço do mesmo produto comercializado no mercado local. Referem-se os informantes ao período de entressafra, quando o preço pago pelo PAA fica abaixo do preço de mercado, ocasionando uma noção de prejuízo. Todavia, há de se considerar que, em período de safra e abundância de oferta, o PAA garante preço justo, superior àquele de mercado. O relato do Agricultor 5 evidência esta correlação: "o preço que eles pagam não é mal, mas aí vem a (...) entressafra já está sendo mal”.

Quanto ao estímuloà produção, relatam que houve aumento na área de produção, diversificação produtiva, aumento da quantidade produzida e também melhora na qualidade dos produtos, tal como evidenciado por julgamentos como: "Passamos a produzir alface e plantamos mais couve. Em geral aumentou, uns 20 \%" (Agricultor 2, 2012); "Comecei a plantar mais e também diversifiquei. Anteriormente eu mexia só com milho, feijão e arroz, hoje eu passei para uns 10 produtos e melhorei bastante a produção" (Agricultor 3, 2012). Estão, aqui, expostas duas relevantes contribuições do PAA à agricultura familiar - indução à diversificação da produção e incentivo ao incremento na qualidade e na produtividade fundamentadas em 
serviços de assistência técnica e extensão rural (ATER), resultado igualmente evidenciado pelos estudos de Ghizelini (2010), Grisa, Schmitt, Mattei, Maluf e Leite (2010) e Delgado, Conceição e Oliveira (2005).

Apesar do destaque concedido pelos autores citados ao benefício do PAA no aumento da produção, é preciso problematizar consequências que pode trazer tal aumento de produção frente a eventual situação de descontinuidade da política. Por essa razão, os informantes relataram perdas de mercadorias após o término de contrato com a CONAB, uma vez que não havia outro mercado para absorver a oferta.

O serviço de ATER no âmbito do PAA e de programas similares de compras governamentais, a exemplo do PNAE, exige que seja contemplada a criação de mercados alternativos, e, ainda, o reconhecimento e fortalecimento de mercados convencionais preexistentes, de modo a reduzir a dependência da comercialização a órgãos governamentais por meio de programas. Esse esforço deve ser acompanhado de um continuo processo de melhoria nos processos produtivos, de modo que os agricultores aumentem qualidade no produto e na produtividade, alcançando mercados mais exigentes e competitivos, ao tempo que fornecem e garantem estabilidade na renda a partir de acesso a programas governamentais. Os relatos abaixo exemplificam o dilema da dependência:

Nós plantamos bastante lá - repolho, o chuchu, essas coisas que a gente levava para lá. Tem muita coisa lá que era para a CONAB. Então, tem muita coisa que nós perdemos. (...) nós estamos com mais de 5 mil quilos de moranga esperando que ela [CONAB/PAA] voltasse, e ela não voltou. Essa mercadoria não tem mercado para ela (Agricultor 4, 2012).

O PAA está parado por causa da liberação de dinheiro. Agora, eu estou só com a escola e a feira e perdendo mercadoria porque está sobrando muita coisa. (...) A CONAB juntava tudo. Nós pegávamos tudo que tinha de excesso lá e entregava (Agricultor 1, 2012).

A gente corre o risco de perder. Eu tenho muita laranja, estou correndo o risco de perder porque eu não tenho comércio para ela. Mandioca eu tenho muita, porque eu plantei para esse fim e corro o risco também de perder porque vai ficando velha. A gente não tendo o programa do PAA, a gente corre o risco de perder muita mercadoria (Agricultor 3, 2012).

Tem que diminuir muita coisa, porque a gente produz, por exemplo, a mandioca. Plantei muita mandioca focada no PAA e tem muita coisa igual. O pomar é focado no PAA e dá um reflexo muito grande porque aí você vai ter que diminuir, né? Vai ter que diminuir aquele produto ali, porque eu vou produzir não sabendo onde vou colocar, não tem incentivo (Agricultor 3, 2012).

Plantar nós continuamos plantando. O difícil é vender o produto. De que adianta plantar e você estar com a horta cheia de tomate se ninguém vai comprar? (Agricultor 2, 2012).

Ficam expostos, assim, embaraços trazidos por programas de compras governamentais à agricultura familiar. Aqui, é factível inferir, não apenas o PAA padece no tocante ao processo de gestão integrada, mas, também, programas congêneres a exemplo do PNAE. Vários componentes interferem na descontinuidade do fluxo. Em primeiro lugar, a $\mathrm{CONAB}$, por alguma razão técnico-burocrática, pode retardar ou sustar o lançamento de chamadas. Restrição financeiro-orçamentária, entrave burocrático na liberação de orçamento e rubrica financeira e ausência temporária de demanda (a exemplo de período de férias escolares e de atividades socioassistenciais) podem explicar a ausência da CONAB na execução do PAA nos termos destacados pelos informantes.

Os agricultores que acessaram o último contrato do Programa de Aquisição de Alimentos em 2010 submeteram um projeto em 2012 que foi aprovado, mas que até a data da pesquisa não havia sido liberado o recurso para o começo da entrega. Diante da demora na liberação de recursos para os projetos aprovados, o presidente da associação acredita que o interesse dos agricultores tende a acabar. Segundo ele, "com essa demora de aprovação do projeto, cada vez mais tá piorando, porque ae já passam a não acreditar mais, é incerto" (Agricultor 2, 2012). A fala do entrevistado demonstra a grande importância do programa, pois os agricultores produziram e aumentaram sua produção acreditando na sua continuidade.

De outro modo, embaraços podem ocorrer a partir da descontinuidade nos serviços de assistência técnica e extensão rural (ATER). Nesse caso, é importante destacar que pequenos agricultores, com baixo grau de escolaridade predominantemente, não têm capacidade técnica para elaborar projetos de acesso a tais 
programas de modo autônomo, dependendo, portanto, de assessoria para tal tarefa. Desse modo, fatos como férias, transferência ou viagem a serviço do técnico, ou, ainda, ruído de comunicação entre o técnico local de ATER e os agricultores podem explicar a interrupção de apresentação de projeto de acesso no prazo e nos termos de dada chamada. Assim, ao tempo que fornecem ao agricultor mercado e preço justo, tais programas governamentais trazem, por outro lado, riscos, vinculados a processos técnico-burocráticos que, aliados ao fluxo irregular de demanda ao longo do ano, suplantam interesses locais de oferta e consumo.

Outro ponto positivo do PAA é a contribuição à promoção da soberania e segurança alimentar e nutricional (SSAN) das famílias no campo a partir da produção para autoconsumo. Todos os agricultores afirmaram que os alimentos entregues via PAA constituem a base alimentar da família. De forma análoga, Delgado et al. (2006) e Zimmermann e Ferreira (2008) identificaram que o PAA tem melhorado a produção para autoconsumo por parte dos agricultores familiares, tanto por promover a valorização de produtos da horta e do quintal, quanto por induzir a diversificação da produção a partir de demandas de mercados institucionais com foco no local. Deste modo, ao alterar hábitos de produção e autoconsumo de agroalimentos junto a populações em situação de vulnerabilidade, o PAA estabelece diálogo com outra política, qual seja, a de soberania e segurança alimentar e nutricional (Lei $\mathrm{N}^{\circ} 11.346$, de 15 de setembro de 2006). Nesse sentido, a expressão a seguir é ilustrativa:

Nós passamos a se alimentar principalmente das verduras e legumes, porque antes a gente não tinha muita opção. Hoje a gente diversificou e a gente produz, por exemplo, um inhame, que é um bom alimento, e a gente passou a se alimentar dele muito (...). A gente passou a se alimentar de outros produtos que a gente não produzia e que passou a produzir (Agricultor $3,2012)$.

É positivo, portanto, o processo indutivo do PAA no aprimoramento das condições de produção e consumo de agroalimentos em áreas rurais. Os produtos que estavam sendo cultivados nas propriedades eram destinados tanto para comercialização quanto para o autoconsumo. Desse modo, ao promover a diversificação da produção o PAA aparece induzindo mudanças nos hábitos alimentares, avançando em indicadores de segurança alimentar e nutricional, e contribuindo para fortalecer a soberania alimentar dos agricultores.

Fica evidente que mudanças precisam ocorrer no conteúdo dos serviços de ATER. É pertinente assumir que a indução à diversidade, aliada ao incentivo à melhoria na qualidade e na produtividade de agroalimentos é resultado positivo dos serviços de ATER, até mesmo pelo fato de que tal iniciativa aparece influenciando hábitos alimentares entre agricultores familiares, contribuindo para avanços em indicadores de segurança alimentar e nutricional.

As potencialidades elencadas neste estudo estão comprometidas em virtude da brusca redução no orçamento do Programa para os anos recentes, passando de quase $\mathrm{R} \$ 800$ milhões em 2012, ano de realização da pesquisa, para $\mathrm{R} \$ 210$ milhões em 2018. Além da crise fiscal, esta redução é resultado de uma atuação mais incisiva dos órgãos estatais, por vezes descontextualizadas das especificidades da agricultura familiar. Sua execução se tonou mais intensa em regras formais e documentos exigidos, assim como a fiscalização se tornou mais energética e menos flexível (Grisa, Kato, Flexor, \& Zimmermann, 2017). Essa descontinuidade pode comprometer parte dos esforços já realizados pelo PAA no sentido de promover a organização dos agricultores em associações, induzir à estruturação produtiva das unidades familiares, ampliar a capacidade de oferta e conferir escala e diversidade à produção, além de todo o trabalho realizado na articulação local entre produtores e unidades recebedoras beneficiadas com entrega dos alimentos (Valadares \& Souza, 2015).

\section{Considerações Finais}

O PAA tem contribuído para alterar estruturas de mercado e a relação entre agentes econômicos do segmento da agricultura familiar, apresentando efeitos positivos nos preços pagos aos produtores, viabilizando e 
fortalecendo organizações locais, promovendo a organização social e colaborando para o reconhecimento da importância da agricultura familiar no abastecimento alimentar local. Apesar disso, a renda gerada ainda é baixa, principalmente em virtude de irregularidades nos fluxos de execução do programa e de pagamentos ao agricultor, resultando na perda da produção destinada ao PAA e comprometendo a renda. São limitações fortemente relacionadas a aspectos burocráticos do programa.

Há excesso de etapas nos processos burocráticos e a exigência de vários documentos dos agricultores familiares se apresenta como barreira no acesso ao PAA. Além disso, é relevante considerar a baixa escolaridade dos agricultores e a restrita capacidade para gerir adequadamente os mecanismos do programa. Nesse sentido, torna-se oportuna a criação de mecanismos de auxílio ao agricultor quanto ao gerenciamento do conteúdo e dos procedimentos do PAA por meio do fortalecimento de serviços de assistência técnica e extensão rural (ATER), aqui pautada pelos informantes na pessoa jurídica da EMATER. Além disso, é necessário o aperfeiçoamento do processo de divulgação dos resultados das chamadas, de modo a facilitar o planejamento da produção agrícola e a elaboração de cardápios pelas entidades receptoras dos produtos, no caso do PAA/CDS.

A análise da implementação do PAA/CDS a partir de um caso, no espaço rural mineiro, permitiu a visualização de efeitos positivos e gargalos na operacionalização. Apesar dos diversos entraves encontrados, que têm dificultado a operacionalização e a obtenção de resultados mais promissores, o PAA deve ser tomado como relevante instrumento de política pública com elevado potencial de fortalecimento da agricultura familiar. Os resultados apontam, todavia, para a necessidade de mudanças na gestão de fluxos, na sincronia entre produção e comercialização, especificamente pela dependência que se forma entre acesso a chamadas públicas e escoamento de produtos.

No caso aqui pautado, os cinco informantes adotavam sistema de produção e vendas destinado regularmente para feiras e para mercado futuro, "em vista", a exemplo do PAA. Em geral, destinavam para os mercados os produtos que cultivavam para o autoconsumo. Foram encontradas situações em que as famílias passaram a cultivar novos produtos para responder a demandas de mercado ou incrementaram a produção de alimentos já cultivados nos estabelecimentos, mesmo que mediante comercialização limitada. Em ambos os casos, o PAA apareceu reforçando a diversificação da produção.

Os agricultores indicaram como fator limitante a diferença dos preços de referência da CONAB e os praticados no estado e no município. Além do preço, os agricultores apontaram que o valor repassado por agricultor familiar ( $\mathrm{R} \$ 4.500,00$ por pessoa física no projeto de 2010) estava subestimado. Apesar disso, tal valor contribuía para a renda familiar especialmente para os agricultores familiares menos capitalizados e com maiores dificuldades de inserção no mercado. Ademais, os agricultores apontaram outros aspectos negativos que desestimulavam, mas não impediam de produzir alimentos para PAA, a exemplo de sucessivos atrasos no pagamento por parte da CONAB. Mesmo diante de atrasos, preferiam os agricultores continuar entregando os produtos uma vez que a interrupção traria prejuízos maiores. A burocracia, tanto na prestação de contas quanto na aprovação e liberação dos recursos, aliada à precariedade no processo de comunicação e na transparência e à inexistência de um órgão federal responsável pelo programa em nível local, no município de Viçosa/MG, foram outros elementos referidos pelos informantes.

Diante do quadro aqui delineado, como agenda de pesquisa, se sugere investigar como outras políticas como o Pronaf no âmbito da renda, e o PNAE no âmbito da garantia da comercialização e geração de renda - podem contribuir, de forma integrada, para mitigar os problemas elencados e potencializar os resultados positivos do PAA. A implantação do Programa de Aquisição de Alimentos em Viçosa aponta, portanto, para a necessidade de mais estudos que possam contribuir para a desburocratização do programa e para sua consolidação como política pública eficiente que contribua para o desenvolvimento rural. Para verificar o efeito do programa ao logo do tempo seria interessante o contínuo monitoramento dos produtores. 


\section{REFERÊNCIAS}

Alves, V. O., Vieira, N. dos S., Silva, T. C. da, \& Ferreira, P. R. (2011). O associativismo na agricultura familiar dos estados da Bahia e Minas Gerais: Potencialidades e desafios frente ao Programa de Aquisição de Alimentos (PAA). Administração Pública e Gestão Social, 3(1), 66-88.

Andrews, C. W. (2004). Anti-poverty policies in Brazil: reviewing the past ten years. International Review of Administrative Sciences, 70(3), 477-488.

Becker, C., \& dos Anjos, F. S. (2010). Segurança alimentar e desenvolvimento rural: limites e possibilidades do Programa de Aquisição de Alimentos da agricultura familiar, em municípios do Sul gaúcho. Segurança Alimentar e Nutricional, 17(1), 61-72.

Botelho Filho, F. B., Carvalho, A. D., Schneider, S., Fialho, M. A. V., Müller, A. L., Mattei, L., ... Silva, A. G. da. (2007). Estudo do impacto do PAA sobre os arranjos econômicos nas regiōes nordeste e sul do Brasil. Em R. Paes-Sousa \& J. Vaitsman (Eds.), Sintese das Pesquisas de Avaliação de Programas Sociais do MDS (5. ed.), 65-68. Brasília, DF: MDS.

Buainain, A. M., Romeiro, A. R., \& Guanziroli, C. (2003). Agricultura familiar e o novo mundo rural. Sociologias, 5(10), 312-347.

Camargo, B. V., \& Justo, A. M. (2013). Tutorial para uso do software de análise textual IRAMUTEQ. Santa Catarina: Universidade Federal de Santa Catarina.

Campos, A. de, \& Bianchini, V. (2014). Agricultura Familiar passa a ser prioridade de Estado. Em M. E. Del Grossi \& D. R. Kroeff (Eds.), PAA: 10 anos de Aquisição de Alimentos (p. 280). Brasília: MDS.

Carvalho, D. G. de. (2009). Licitações Sustentáveis, Alimentação Escolar e Desenvolvimento Regional: Uma Discussão Sobre O Poder de Compra Governamental a Favor da Sustentabilidade. Planejamento e Políticas Públicas, 1(32), 115-148.

Cerqueira, P. da S., Rocha, A. G. P., \& Coelho, V. P. (2006). Agricultura familiar e políticas públicas: algumas reflexões sobre o Programa de Aquisição de Alimentos no estado da Bahia. Revista Desenbahia, 3(5), 55-78.

CONAB (2017). Cartilha de compra da Agricultura familiar com doação Simultânea-Cpr-doação. Brasília: Companhia Nacional de Abastecimento.

Cordeiro, A. (2007). Resultados do programa de aquisição de alimentos - PAA: a perspectiva dos beneficiários. Brasília, DF: CONAB.

Delgado, G. C., Conceição, J. C., \& Oliveira, J. J. de. (2006). Relatório de Avaliação do Programa de Aquisição de Alimentos da Agricultura Familiar (PAA). Cadernos do CEAM, 6, 35-52.

Delgado, G. C. (2005). A Questão Agrária no Brasil, 1950-2003. Em Questão social e politicas sociais no Brasil contemporâneo (pp. 51-90). Brasília, DF: Ipea.

Deves, O. D., \& Rambo, A. G. (2013). Mercados Institucionais e a comercialização de alimentos na agricultura familiar: O Programa de Aquisição de Alimentos no município de São Pedro do Butiá - RS - BRASIL. Redes - Revista de Desenvolvimento Regional, 18(1), 147-166.

Dias, T. F., Nunes, E. M., Torres, F. de L., \& Torres, A. C. M. (2013). O programa de aquisição de alimentos da agricultura familiar (PAA) como estratégia de inserção socioeconômica: o caso do Território da Cidadania Sertão do Apodi (RN). Revista Brasileira de Gestao e Desenvolvimento Regional, 9(3), 100-129.

Freitas, A. F. de. (2017). Dinâmicas locais de implementação do Programa Nacional de Alimentação Escolar: Uma abordagem relacional. Viçosa: Universidade Federal de Viçosa.

Freitas, A. F. De, Freitas, A. F. De, \& Dias, M. M. (2012). Mudanças conceituais do desenvolvimento rural e suas influências nas políticas públicas. Revista de Administração Pública, 46(6), 1575-1598.

Gazolla, M., \& Schneider, S. (2013). Qual «fortalecimento» da agricultura familiar?: uma análise do Pronaf crédito de custeio e investimento no Rio Grande do Sul. Revista de Economia e Sociologia Rural, 51, 45-68.

Ghizelini, A. A. M. (2010). Atores sociais, agricultura familiar camponesa e o espaço local: uma análise a partir do Programa de Aquisição de Alimentos (Tese de Doutorado). Curitiba, Universidade Federal do Paraná. 
Gil, A. C. (2017). Como elaborar projetos de pesquisa (6. ${ }^{a}$ ed.). São Paulo: Atlas.

Godoy, C. M. T., Perez, F. I. C., Wizniewiski, J. G., Guedes, A. C., \& Moraes, C. S. (2010). Juventude rural, envelhecimento e o papel da aposentadoria no meio rural: A realidade do município de Santa Rosa/RS. Em $48^{\circ}$ Congresso da Sociedade Brasileira de Economia, Administração e Sociologia Rural. Campo Grande: SOBER.

Graziano da Silva, J., Del Grossi, M. E., \& França, C. G. de. (2012). Fome zero. (J. Graziano da Silva, M. E. Del Grossi, \& C. G. de França, Eds.). Brasília: NEAD Especial.

Grisa, C. (2010). As redes e as instituições do Programa de Aquisição de Alimentos ( PAA ). Revista Brasileira de Gestão e Desenvolvimento Regional, 6(2), 97-129.

Grisa, C. (2012). Políticas públicas para a Agricultura Familiar no Brasil:produção e institucionalização das ideias (Tese de dotorado). Universidade Federal Rural do Rio de Janeiro, Seropédica.

Grisa, C., Kato, K. Y. M., Flexor, G. G., \& Zimmermann, S. A. (2017). Capacidades estatais para o desenvolvimento rural no Brasil\#: análise das políticas públicas para a agricultura familiar Capacidades estatais para o desenvolvimento rural no Brasil\#: análise das políticas públicas para a agricultura familiar. Sociedade e Cultura, 20(1), 13-38.

Grisa, C., Schmitt, C. J., Mattei, L. F., Maluf, R., \& Leite, S. P. (2010). O programa de aquisição de alimentos (PAA) em perspectiva: apontamentos e questôes para o debate. Retratos de Assentamentos, 13, 321-342.

Grisa, C., Schmitt, C. J., Mattei, L. F., Maluf, R. S., \& Leite, S. P. (2011). Contribuições do Programa de Aquisição de Alimentos à segurança alimentar e nutricional e à criação de mercados para a agricultura familiar. Revista Agriculturas, 8(3), 34-41.

Grisa, C., \& Schneider, S. (2014). Três Gerações de Políticas Públicas para a Agricultura Familiar e Formas de Interação entre Sociedade e Estado no Brasil. Revista de Economia e Sociologia Rural, 52(Sulp. 1), 125-146.

Hespanhol, R. A. D. M. (2013). Programa de Aquisição de Alimentos: Limites e potencialidades de políticas de segurança alimentar para a agricultura familiar. Sociedade e Natureza, 25(3), 469-483.

IBGE. (2006). Censo Agropecuário. Rio de Janeiro: Ministério do Planejamento, Orçamento e Gestão.

IBGE. (2011). Censo Demográfico 2010. Rio de Janeiro: Instituto Brasileiro de Geografia e Estatística.

Kageyama, A. A., Bergamasco, S. M. P. P., \& Oliveira, J. T. A. De. (2013). Uma Tipologia dos Estabelecimentos Agropecuários do Brasil a partir do Censo de 2006. Revista de Economia e Sociologia Rural, 51(1), 105-122.

Kingdon, J. W. (2014). Agendas, Alternatives, and Public Policies (2. ed.). Harlow: Pearson.

Lahlou, S. (2012). Text mining methods\#: an answer to Chartier and Meunier.Papers on Social Representation, 20(38), $1-7$.

Mattei, L. (2007). Programa de Aquisição de Alimentos da Agricultura Familiar (PAA) - Antecendentes, Concepção e Composição Geral do Programa. Cadernos do CEAM, 7, 33-44.

MDS (2018). Portal do Ministério do Desenvolvimento Social. Obtido 7 de Março de 2018, de http://mds.gov.br/a ssuntos/seguranca-alimentar/programa-de-aquisicao-de-alimentos-paa

Mielitz, C. (2014). Dez anos de PAA e a Constituição de uma Estratégia Nacional de Segurança Alimentar. Em M. E. Del Grossi \& D. R. Kroeff (Eds.), PAA: 10 anos de Aquisição de Alimentos (p. 280). Brasília: MDS.

Müller, A. L. (2007). Contrução Das Políticas Públicas Para Agricultura Familiar No Brasil: O Caso Do Programa De Aquisição De Alimentos. Universidade Federal do Rio Grande do Sul.

Müller, A. L., Fialho, M. A. V., \& Schneider, S. (2007). A inovação institucional e a atuação dos atores locais na implementação do Programa de Aquisição de Alimentos no Rio Grande do Sul. Sociedade e Desenvolvimento Rural, 1(1), 1-22.

Muller, A. L., Silva, M. K., \& Schneider, S. (2012). A Construção das Políticas Publicas Para Agricultura Familiar no Brasil: O Programa Aquisição de Alimentos. Estudos Sociedade e Agricultura, 20(1), 106-138.

Paula, M. M. de, Kamimura, Q. P., \& Silva, J. L. G. da. (2014). Mercados institucionais na agricultura familiar: dificuldades e desafios. Revista de Politica Agricola, 23(1), 33-43. 
Porto, S. I., Soares, E. S., Soares, J. F., Cruz, K. C. M. S., Viegas, G. L., \& Viana, C. (2014). Programa de Aquisição de Alimentos (PAA): dez anos de uma política pública múltipla e inovadora. Em M. E. Del Grossi \& D. R. Kroeff (Eds.), PAA: 10 anos de Aquisição de Alimentos (p. 280). Brasília, DF: MDS.

Salgado, R. J. dos S. F., \& Dias, M. M. (2013). Análise da influência do Programa de Aquisição de Alimentos sobre a qualidade de vida de agricultures familiares do município de Viçosa/MG. Perspectivas em Políticas Públicas, 6(11), 65-91.

Sambuichi, R. H. R., Galindo, E. P., Oliveira, M. A. C. de, \& Moura, A. M. M. de. (2014). Compras públicas sustentáveis e agricultura familiar: a experiência do Programa de Aquisição de Alimentos (PAA) e do Programa Nacional de Alimentação Escolar (PNAE). Em R. H. R. Sambuichi, A. P. M. da Silva, M. A. C. de Oliveira, \& M. Savian (Eds.), Politicas agroambientais e sustentabilidade: desafios, oportunidades e lições aprendidas (p. 273). Brasília: Ipea.

Schimitt, C. J., \& Guimarães, L. A. (2008). O mercado institucional como instrumento para o fortalecimento da agricultura familiar de base ecológica. Agriculturas, 5(2), 7-13.

Schmitt, C. J. (2014). O Programa de Aquisição de Alimentos em assentamentos de reforma agrária: implantação, impactos e perspectivas. Em M. E. Del Grossi \& D. R. Kroeff (Eds.), PAA: 10 anos de Aquisição de Alimentos (p. 280). Brasília: MDS.

Schneider, S., Conterato, M. A., Koppe, L. R., \& Silva, C. C. e. (2006). A pluriatividade e as condições de vida dos agricultores familiares do Rio Grande do Sul. Em A Diversidade da Agricultura Familiar (pp. 137-165). Porto Alegre: UFRGS.

Schneider, S., Cruz, F. T. da, \& Matte, A. (2016). Estratégias alimentares e de abastecimento: desafios e oportunidades para as cidades e para o meio rural. Em F. T. da Cruz, A. Matte, \& S. Schneider (Eds.), Produção, consumo e abastecimento de alimentos: Desafios e novas estratégias (1 $1^{\mathrm{a}}$, p. 324). Porto Alegre: Editora da UFRGS.

Schneider, S., Mattei, L., \& Cazella, A. A. (2004). Histórico, caracterização e dinâmica recente do PRONAF Programa Nacional de Fortalecimento da Agricultura Familiar. Em S. Schneider \& P. E. Moruzzi (Eds.), Politicas Públicass e Participação Social no Brasil Rural (pp. 21-50). Porto Alegre: UFGRS.

Silva, T. C., Ferreira, P. R., \& Amodeo, N. B. P. (2014). A Importância do Programa de Aquisição de Alimentos (PAA) nos territórios da cidadania dos Estados de Minas Gerais e da Bahia\#: Criação de novos mercados a partir da visão dos Agentes de Assistência Técnica e Extensão Rural ( ATER ). Mundo Agrario, 15(29), 1-21.

Simão, G. L., \& Silva, E. A. (2014). Habilidade Social Estratégica e Políticas Públicas Coproduzidas - Estudo Multicaso do Programa de Aquisição de Alimentos. Em ANPAD (Ed.), XXXVIII Encontro da ANPAD. Rio de Janeiro.

Simão, G. L., Silva, E. A., \& Silveira, S. de F. R. (2014). Grau de cobertura do Programa de Aquisição de Alimentos (PAA) junto aos agricultores familiares do estado de Minas Gerais. Revista de Economia e Sociologia Rural, 52(3), 533-548.

Sousa, A. A. de, Silva, A. P. F. da, Azevedo, E. de, \& Ramos, M. O. (2015). Cardápios e sustentabilidade: ensaio sobre as diretrizes do Programa Nacional de Alimentação Escolar. Revista de Nutrição, 28(2), 217-229.

Valadares, A. A., \& Souza, M. G. P. de. (2015). A trajetória recente do Programa de Aquisição de Alimentos da Agriucltura Familiar (PAA): uma análise das mudanças normativas e institucionais que deram nova inflexão ao programa. IPEA - Nota Técnica, 21, 1-35.

Vieira, D. de F. A., \& Del Grossi, M. E. (2010). Influência do Programa de Aquisição de Alimentos na comercialiação dos produtos da agricultura familiar: o caso do município de Paracatu em Minas Gerais. Sociedade e, 4(2), 21-48.

Zimmermann, S. A., \& Ferreira, A. P. L. (2008). El Programa de Adquisición de Alimentos de la Agricultura Familiar en Mirandiba-PE. Em G. Scotto (Ed.), Aun hay tiempo para el sol: pobrezas rurales y programas sociales (p. 144). Rio de Janeiro: ActionAid.

\section{BY-NC-SA}

